\title{
POPULATIONS OF LARVAE OF THE JACK PINE BUDWORM ${ }^{2}$
}

\author{
BY R. R. LEJEUNE and W. F. BLACK
}

\author{
Forest Insect Laboratory, Winnipeg, Manitoba
}

The jack pine budworm, Choristoneura sp., was first observed in Michigan in 1923 (1). By 1936 this insect was damaging large areas of outcrop jack pine in northwestern Ontario and causing severe mortality in limited areas. Since then the insect has been a perennial problem in parts of Manitoba and northwestern Ontario.

The jack pine budworm differs from the spruce budworm, Cboristoneura fumiferana (Clem.), in several respects, including host specificity, feeding habits and seasonal development. Second-instar larvae of the jack pine budworm usually emerge from hibernacula when jack pine pollen is being shed. The larvae begin to feed soon after emergence, the favoured food being the male cones. Although some larvae inhabit the cones throughout the entire feeding period, there is a pronounced movement to new foliage after the pollen is shed. The spruce budworm larvae emerge at the time of the swelling of balsam and white spruce buds. The larvae mine the old needles or feed on the young buds. They limit the amount of new growth by interfering with bud development and are forced to feed extensively on old foliage. Because the young jack pine budworm larvae feed mainly on male cones, new foliage is consumed only after bud development is well advanced. Only where heavy populations occur is the damage to old needles appreciable. Therefore, the jack pine budworm does not cause as heavy mortality as does the spruce budworm in outbreaks of comparable intensities. Damage by the jack pine budworm consists mainly in the formation of stag-headed trees and probable reduction in growth.

Graham (1) in 1935, first drew attention to the association between the jack pine budworm and male jack pine flowers. The study described in the present paper was undertaken to obtain quantitative evidence on this relationship. The work was carried out from 1942 to 1948 at Hawk Lake, Ontario.

\section{Methods}

The number of budworm larvae and the abundance of male cones were estimated annually from 1942 to 1948 , with one exception. The abundance of male cones was not estimated in 1943 because it was not realized then that the number of flowering trees and the degree of flowering fluctuate widely.

The abundance of male cones was estimated during the peak period of pollen shedding, usually early in June. Between 600 and 700 trees, which included most of those in the study area, were tallied into Classes A, B and $C$, in accordance with the abundance of male cone clusters on them. The trees were situated in three types of stands: pure jack pine on sandy soil,

1. Contribution No. 2677 . . . Division of Entomology, Science Service, Department of Agriculture, Ottawn, Canada. "The full title of this article is, "The Relationship between Abundance of Male Cones of Jack Pine and Populations of Larvae of the Jack Pine Budworm, Choristoneura sp. (Lepidoptera: Tortricidae) 
jack pine on rock outcrop, and mixed jack pine, spruce and hardwoods. Accordingly, each type was considered a sub-area.

Class A.-Trees which upon first glance are seen to bear large numbers of male cone clusters; at least every second or third branch should bear a number of clusters for the trees to be so classified.

Class B.-Trees which after some scrutiny are found to bear two or three branches heavily laden with male cone clusters or which have a few clusters on most branches.

Class C.-Trees upon which no male cone clusters, or only a few scattered clusters, are visible on close scrutiny from the ground.

Table I

Percentage of Jack Pine Trees in the Hawk Lake, Ontario, Area Falling into Each Class of Abundance of Male Cones, 1942 and 1944-8.

\begin{tabular}{|c|c|c|c|c|}
\hline Year & $\begin{array}{c}\text { No. of } \\
\text { Trees } \\
\text { Examined }\end{array}$ & Class $A$ & Class B & Class $C$ \\
\hline 1942 & 14 & 12.9 & 16.3 & 70.8 \\
1944 & 19 & 14.3 & 16.7 & 69.0 \\
1945 & 25 & 1.3 & 8.2 & 90.5 \\
1946 & 42 & 21.0 & 8.5 & 70.5 \\
1947 & 20 & 13.1 & 38.9 & 48.0 \\
1948 & 25 & 16.8 & 40.8 & 42.4 \\
\hline
\end{tabular}

Trees sampled for larvae were selected at random throughout the area and the class was recorded for each. An effort was made to sample 20 to 25 trees annually but this was not always possible because of time limitations.

For each sub-area, the total number of trees and the number of each class to be sampled were determined on a proportional basis, according to the number of trees classified and the percentage of each class in each subarea. Trees were selected at random in the sub-areas until the required number of each class had been sampled.

A standard method of sampling for budworm larvae was developed. It was modified and improved as the work progressed, but essentially the same procedure was employed throughout. Four branches were removed from the crown of each sample tree, two from the upper half, and two from the lower half. Fifty expanded terminal buds were counted, beginning at the periphery of each branch. Where a male cone cluster occurred it was invariably associated with a terminal bud, and the cluster and the bud were recorded as one unit. Then the 50 units were examined for budworm larvae. From these data, the budworm population was computed on the basis of larvae per 100 terminals for each of the tree classes. Finally, the average population for the Hawk Lake area for any given year was determined as a weighted mean. RESULTS

Table I shows the percentage of trees in each class in the Hawk Lake area in 1942 and from 1944 to 1948. No count was made in 1943. In 
each year most of the trees fell in Class $C$, though there were almost as many in Class B as in Class C for 1947 and 1948.

The average number of budworm larvae per 100 terminals for each tree class in 1942 and from 1944 to 1948 is shown in Table II.

\section{Table II}

Populations of Larvae of the Jack Pine Budworm on Trees in the Hawk Lake, Ontario, Area in Each Class of Abundance of Male Cones, 1942 and 1944-8.

\begin{tabular}{|c|c|c|c|}
\hline \multirow{2}{*}{ Year } & \multicolumn{3}{|c|}{ Number of Larvae per 100 Terminals } \\
\cline { 2 - 4 } & Class $A$ & Class $B$ & Class $C$ \\
\hline 1942 & 11.6 & 8.0 & 6.3 \\
1944 & 60.8 & 45.3 & 20.2 \\
1945 & 17.5 & 6.6 & 6.8 \\
1946 & 2.9 & 2.5 & 0.4 \\
1947 & 9.6 & 14.5 & 5.1 \\
1948 & 50.1 & 50.1 & 21.2 \\
Mean & 25.4 & 21.2 & 10.0 \\
\hline
\end{tabular}

The mean values in Table II show that larval populations decrease from the heavily flowering Class $A$ trees to the non-flowering Class $C$ trees. This trend is rather consistent except for minor exceptions in 1945 and 1947. The data were subjected to an analysis of variance. As expected, the difference in larval populations between years is highly significant; but, what is more important, larval populations for the tree classes also differ significantly $(\mathrm{F}=$ 4.96; required for 5 per cent level, 4.10; for 1 per cent level, 7.56). It is, therefore, concluded that the data support the hypotheses that heavier budworm populations occur on trees bearing male flowers and that the number varies directly with the incidence of male flowers.

The fluctuations in larval populations and abundance of flowering trees during the period of study are shown in Fig. 1. In the upper graph, the percentage of male flowering trees for each year is represented by the sum of Class $A$ and Class $B$ trees. For the lower graph, the actual values for the numbers of larvae per 100 terminals were converted to logarithms to reduce extreme variations.

Fig. 1 shows the similarity of trends. The one incongruity occurs in 1946. That these trends should be so similar, in view of the difficulties inherent in estimating insect populations and despite the numerous disturbing factors of the environment, is a strong indication that the relationship is not mere coincidence.

\section{Discussion}

These results add further evidence to the published works of Graham (1) and Hodson and Zehngraff (2), indicating that staminate flowers strongly influence fluctuations of the jack pine budworm. At least one kind of jack pine, the open-growing orchard type, is known to produce male cones in profusion consistently. This type of tree is, therefore; at least partially responsible for the development of budworm 
epidemics. Hodson and Zehngraff(2) showed that in Minnesota suppressed trees tend to produce many male flowers, and they believe that

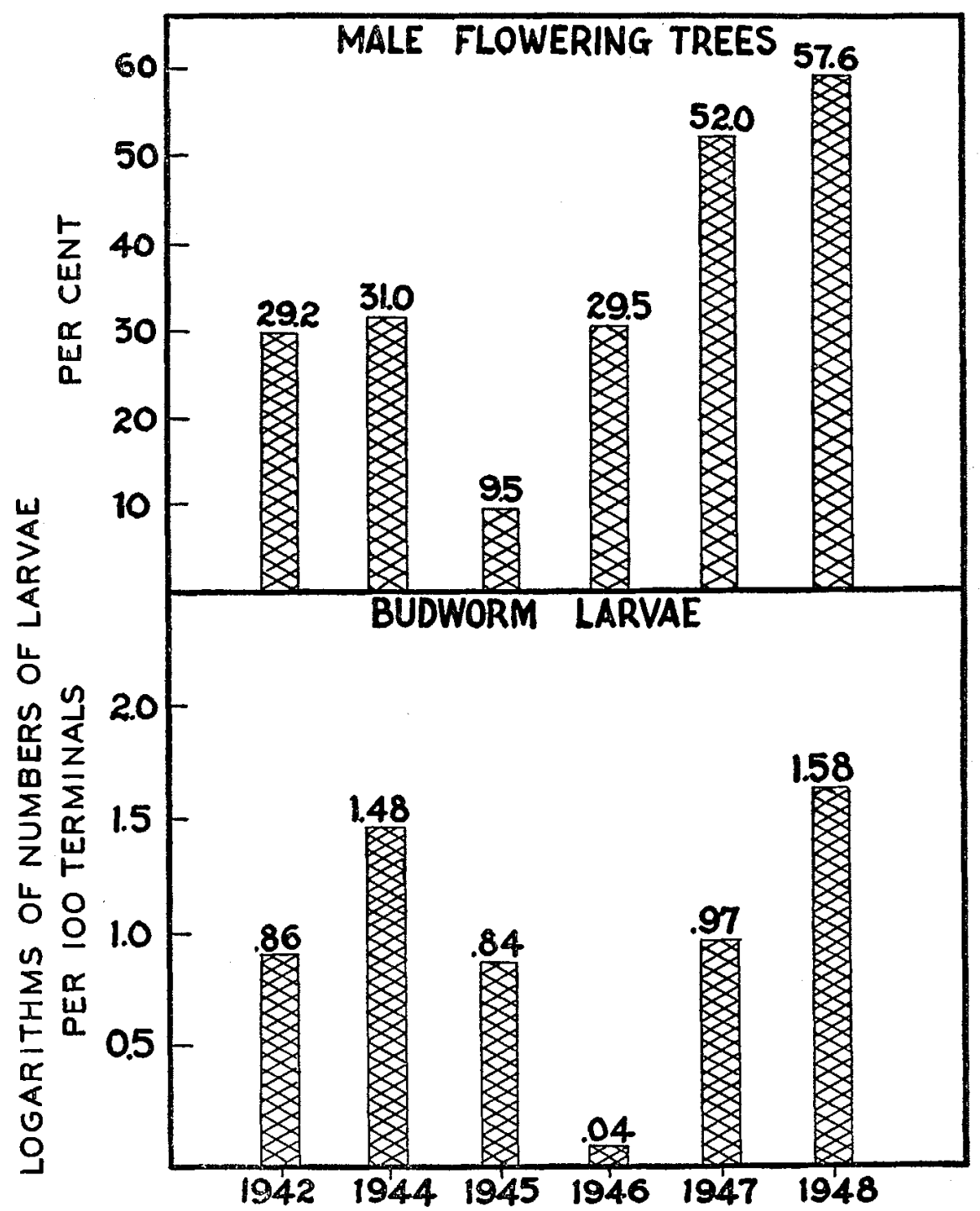

Fig. 1 Number of larvae of the jack pine budworm and abundance of male flowering trees at Hawk Lake, Ontario, in 1942 and from 1944 to 1948.

such trees may serve as reservoirs for budworm populations. The results of these two investigations suggest that more intensive studies on the 
flowering habits of jack pine would lead to the development of practical methods of control by silvicultural methods.

Although no conclusive evidence has been found to explain why jack pine budworm populations are influenced so markedly by pollen production, several explanations have been advanced by those working on the problem. At present, the relationship is attributed to a combination of factors. It is believed that the male cones afford a succulent, readily available food supply for the second-instar larvae at a time when the new foliage is insufficiently developed. Moreover, the cones are thought to provide a more protective habitat and a more favourable micro-climate than the terminal shoots. These factors, together with possible nutritive benefits derived from pollen, are believed to facilitate the establishment of the second-stage larvae in the male flowers. In consequence, there is a higher survival of larvae in male flowers than in terminal buds.

The acceptance of this hypothesis readily explains how budworm populations often fluctuate with such rapidity, and why population increases coincide with pollen increases rather than follow them as would be expected were pollen a factor in raising reproductive potential.

A potential population exists each spring, but this potential is seldom, if ever, realized because of adverse environmental factors. If the budworm population depends largely on favourable feeding sites for maximal survival, the degree to which the potential is realized is related to the abundance of staminate flowers. On the other hand, in the absence of an adequate potential to occupy the available favoured feeding sites, the relationship shown in this paper would obviously break down. This probably occurred in 1946 (Fig. 1). Nevertheless, with an abundance of staminate flowers even small populations can increase rapidly, as witnessed by the rise in the budworm population from 1.1 per 100 terminals in 1946 to 37.4 per 100 terminals two years later.

\section{SUMMARY}

Field studies at Hawk Lake, Ontario, from 1942 to 1948 show that population levels of the jack pine budworm are closely associated with the abundance of male jack pine flowers. This relationship is shown in two ways; (1) in infested areas the greatest number of larvae are found on male flowering trees, and (2) the density of budworm populations and incidence of male flowers and male flowering trees in general fluctuate together.

\section{REFERENCES}

(1) Graham, S. A. The spruce budworm on Michigan pine. University of Michigan School of Forestry and Conservation Bulletin No. 6. 1935.

(2) Hodson, A. C., and P. J. Zehngraff. Budworm control by forest management. Journal of Forestry 44: 198-200. 1946. 